\title{
Perbandingan Penyalaan Sudut Fasa pada SRG Guna Meningkatkan Kinerja untuk Memaksimalkan Keluaran Daya
}

\author{
Rizky Adhitya Nugroho ${ }^{1}$, Slamet Riyadi ${ }^{1}$, Leonardus Heru Pratomo ${ }^{3}$. Florentinus Budi Setiawan ${ }^{4}$ \\ 1,2,3,4 4 Program Studi Teknik Elektro, Universitas Katolik Soegijapranata Semarang \\ Jl. Pawiyatan Luhur Sel. IV No.1, Bendan Duwur, Kec. Gajahmungkur, Kota Semarang, Jawa Tengah 50234 \\ e-mail: rizkyadhinug@gmail.com
}

\begin{abstract}
Abstrak - Dewasa ini teknologi energi terbarukan banyak dikembangkan, salah satunya Pembangkit Listrik Tenaga Bayu (PLTB). PLTB membutuhkan generator untuk menghasilkan energi listrik. Salah satu geneator yang sedang dikembangkan pada PLTB adalah Swicthed Reluctance Generator (SRG). SRG dipilih karena memiliki desain yang sederhana dan perawatan yang mudah. SRG memiliki konstruksi rotor yang terbuat dari inti besi, sehingga membutuhkan parameter lain agar dapat menghasilkan energi listrik. Metode agar SRG dapat menghasilkan energi listrik adalah dengan menjadikan inti besi pada rotor sebagai magnet sementara. Metode single pulse yaitu mengoperasikan konverter asymmetric untuk menyuplai arus pada stator agar menginduksi rotor. Metode ini dilakukan dengan cara mengatur sudut penyalaan fasa pada belitan stator. Pengoperasian SRG membutuhkan informasi impuls arus untuk melihat profil induktansi guna menentukan sudut penyalaan. Pada penelitian ini dilakukan pengaturan sudut penyalaan fasa untuk mengetahui daya keluaran yang optimal. Verifikasi menggunakan perangkat lunak Simulink MATLAB dan pengujian perangkat keras.
\end{abstract}

Kata kunci: Switched Reluctance Generator, MATLAB, SIMULINK, single pulse, asymmetric, renewable energy

\begin{abstract}
Nowadays a lot of the renewable energy developed, one of them is Wind Power Generator. It needs generator to produce electricity. One of the generators developed on wind power generator is SRG which is chosen because of its simple design and easy to maintain. SRG has rotor construction made of iron core, therefore it needs another parameter to produce electricity. The method applied in SRG that it can produce electricity is temporarily magnifying iron core on the rotor (Single Pulse). Single Pulse is operating the asymmetric converter to supply the stream on starter for inducting rotor. This method is implemented by adjusting the angle of phase ignition on the starter coil. SRG operation requires stream impulse information to see the profile induction in order to determine ignition angle. In this research, angle phase ignition adjustment is required to identify the optimized output energy. The verification uses the software of Simulink MATLAB \& hardware assessments.
\end{abstract}

Keywords:Switched Reluctance Generator, MATLAB, SIMULINK, single pulse, asymmetric, renewable energy

\section{PENDAhUluan}

PLTB adalah salah satu energi terbarukan yang tidak menimbulkan polusi. Pada perkembangan teknologi energi terbarukan tidak terlepas dari generator, salah satunya adalah Switched Reluctance Generator (SRG). SRG memiliki kelebihan yaitu konstruksi yang sederhana karena rotor terbuat dari inti besi dan dapat bekerja pada kecepatan tinggi. Untuk kendali pada SRG menggunakan konverter asymmetric 3 fasa dengan IGBT sebagai saklar statis [1]. Dalam menentukan penyalaan sudut fasa membutuhkan informasi impuls arus untuk melihat profil induktansi guna menentukan sudut penyalaan. Metode pengoperasian SRG pada kecepatan tinggi menggunakan metode single pulse, di mana penentuan sudut penyalaan fasa mempengaruhi daya keluaran generator [2].

Pada penelitian ini menyajikan perbandingan dua kondisi sudut penyalaan fasa, Kondisi I dengan interval $30^{\circ}$ dan Kondisi II 31.5. Kondisi II mengalami kondisi overlap karena saklar antar fasa saling bertabrakan. Selain perbandingan sudut, perubahan pada berbagai variasi kecepatan putar rotor juga disajikan. Tujuan dari penelitian ini adalah untuk membandingkan penyalaan sudut fasa untuk meningkatkan kinerja pada SRG. Guna membantu penelitian maka dilakukan simulasi menggunakan MATLAB/SIMULINK. Hasil simulasi akan digunakan sebagai parameter implementasi alat sehingga dapat meningkatkan kinerja pada SRG.

\section{MetOdE}

\section{A. Prinsip Kerja}

Pada dasarnya SRG tidak dapat menghasilkan energi listrik hanya dengan diputar oleh energi kinetik, karena rotor terbuat dari inti besi[3]. Metode magnetisasi pada rotor dapat digunakan agar SRG dapat menghasilkan energi 
listrik. Persamaan tegangan pada setiap fasa disajikan pada (1)

$$
V=R_{p h} i_{p h}+L_{p h} \frac{d i_{p h}}{d t}+\omega r \frac{d \varphi_{p h}}{d \theta}
$$

di mana $\mathrm{V}, \mathrm{R}_{\mathrm{ph}}, \mathrm{i}_{\mathrm{ph}}, \mathrm{L}_{\mathrm{ph}}, \theta$ dan $\omega$ adalah tegangan, resistansi, arus fasa, induktansi fasa, posisi rotor dan kecepatan putaran rotor.

Inti besi dari rotor akan terinduksi setelah diberikan injeksi arus sehingga menghasilkan fluksi. Persamaan backEMF (electromotive force) dapat ditunjukkan pada Persamaan (2):

$$
e=\omega \cdot i_{p h} \frac{d \phi}{d t}
$$

di mana e, $\mathrm{i}_{\mathrm{ph}}, \omega$ dan $\mathrm{d} \phi / \mathrm{dt}$ adalah back-EMF, arus fasa, kecepatan rotor dan perubahan fluksi terhadap waktu[4]. Untk dapat bekerja SRG membutuhkan konverter untuk memberikan eksitasi pada belitan stator. Konverter yang digunakan merupakan konverter asymmetric. Konverter asymmetric berkerja menggunakan dua mode operasi yaitu magnetizing dan demagnetizing yang akan dijelaskan sebagai berikut :

\section{B. Magnetizing}

Magnetizing merupakan proses di mana rotor pada SRG dijadikan sebagai magnet sementara. Mode ini dilakukan dengan mengaktifkan kedua saklar secara bersamaan, sehingga belitan stator akan menerima supply dari sumber Direct Current (DC) [5]. Mode magnetizing disajikan pada Gambar 1.

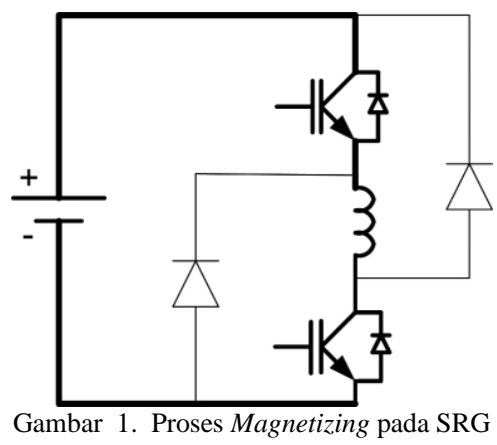

\section{Demagnetizing}

Demagnetizing terjadi setelah proses magnetizing pada belitan stator. Mode ini dilakukan dengan memadamkan kedua saklar secara bersamaan, sehingga energi yang tersimpan pada belitan stator dapat mengalir ke beban melalui dioda[6]. Mode demagnetizing ditunjukkan pada Gambar 2.

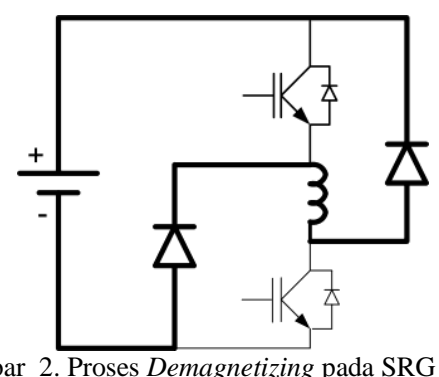

D. Impuls Arus Untuk Menentukan Profil Induktansi

Dalam menentukan sudut penyalaan pada belitan stator dibutuhkan profil induktansi pada SRG. Profil induktansi dapat diketahui dengan melihat impuls arus yang dihasilkan melalui pemberian pulsa Pulse Width Modulation (PWM) berfrekuensi tinggi pada salah satu belitan fasa. Sinyal impuls arus menghasilkan nilai yang berbanding terbalik dengan karakteristik profil induktansi[7]. Impuls arus pada SRG ditunjukkan pada Gambar 3.

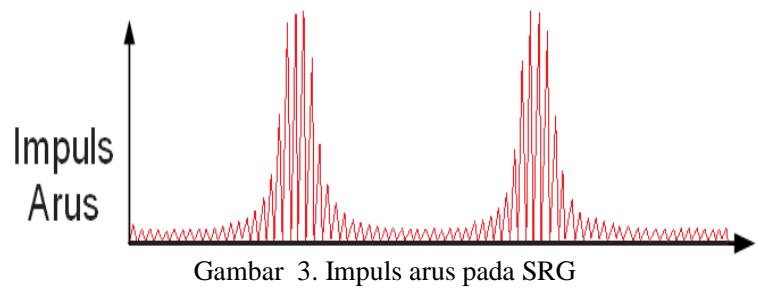

Nilai impuls arus dapat dihasilkan dengan persamaan (3), (4).

$$
\begin{aligned}
& L_{p h}=V_{d c} \frac{\Delta t_{o n}}{i_{i m p}} \\
& i_{i m p}=\frac{V_{d c}}{L_{p h}} \Delta t_{o n}
\end{aligned}
$$

Di mana $\mathrm{L}_{\mathrm{ph}}, \mathrm{V}_{\mathrm{DC}}, \mathrm{i}_{\text {imp }}$ dan $\Delta \mathrm{t}_{\mathrm{on}}$ adalah induktansi, sumber tegangan, impuls arus dan waktu pemberian pulsa

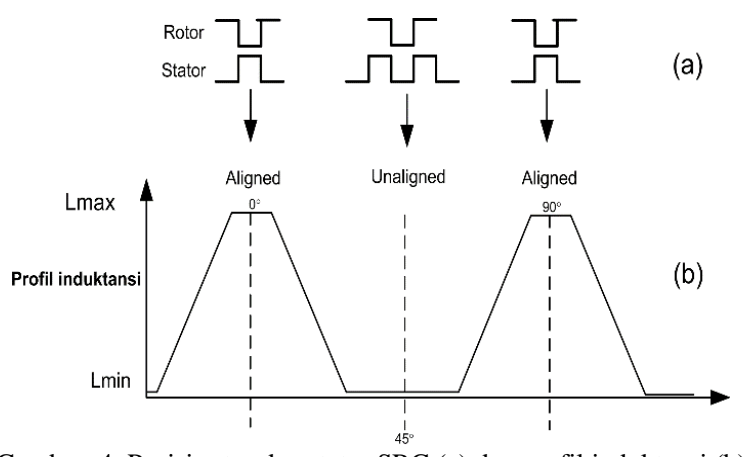

Gambar 4. Posisi rotor dan stator SRG (a) dan profil induktansi (b)

Pada Gambar 4 menunjukkan posisi rotor dan stator SRG (a), profil induktansi (b). SRG beroperasi ketika induktansi menurun dimana posisi rotor sejajar (aligned) akan meninggalkan stator pada posisi tidak sejajar (unaligned). Dalam satu putaran SRG menghasilkan empat profil induktansi karena satu putaran diwakilkan $360^{\circ}$ mekanik dan terdapat empat rotor pada konstruksi generator sehingga setiap profil induktansi sebesar $90^{\circ}$ mekanik[8].

\section{E. Penentuan Sudut Penyalaan Fasa SRG}

Penentuan sudut penyalaan yang tepat sangat penting untuk mendapatkan daya keluaran yang optimal. Sudut penyalaan 
fasa, arus fasa dan arus sumber DC (Direct Current) disajikan pada Gambar 5

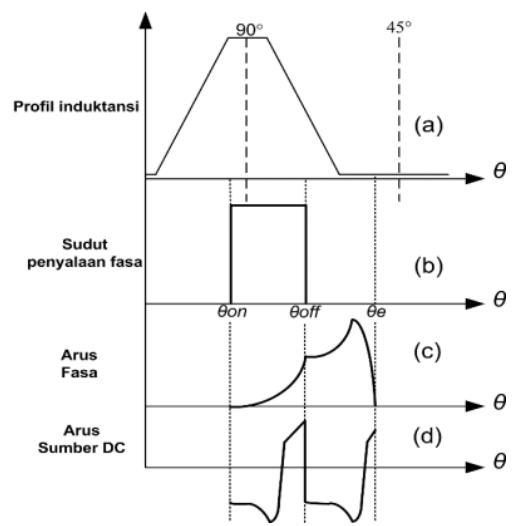

Gambar 5. (a) Profil Induktansi (b) sudut penyalaan fasa, (c) arus fasa, (d) arus sumber DC

Energi dari sumber DC akan membuat fluksi magnet selama magnetisasi, $\theta_{\text {on }} \leq \theta_{\leq} \theta_{\text {off }}$ lalu mengirimkan energi kembali dari penggerak ke sumber DC selama generating, $\theta_{\text {off }} \leq \theta_{\leq} \theta_{\mathrm{e}}$ [9]. Kemiringan arus fasa setelah kondisi saklar dimatikan menghasilkan nilai back-EMF yang lebih besar maka ini menandakan keluaran daya pada SRG bekerja secara optimal[10].

\section{HASIL DAN PEMBAHASAN}

Berdasarkan metode penelitian maka dilakukan simulasi menggunakan perangkat lunak Simulink. Hasil simulasi akan dijadikan parameter implementasi prototype

\section{A. Hasil Simulasi}

Pada simulasi ini mencakup SRG, konverter jenis asymmetric 3 fasa, sensor posisi, mechanical shaft dan mesin DC sebagai pengganti energi kinetik. Rangkaian simulasi ditunjukkan pada Gambar 6.

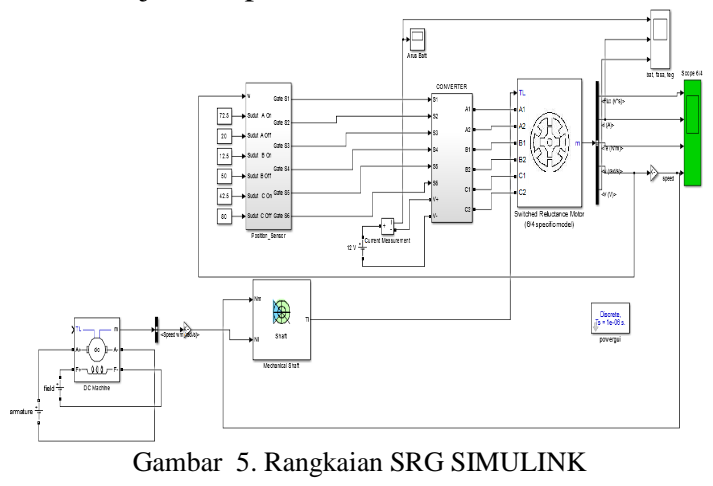

Parameter yang digunakan pada simulasi disajikan pada Tabel 1

Tabel 1. Parameter simulasi SRG

\begin{tabular}{lcc}
\hline \multicolumn{1}{c}{ Parameter } & Nilai & Satuan \\
\hline Stator & 6 & - \\
Rotor & 4 & - \\
Resistansi & 3.3 & Ohm \\
Induktansi & 1.4 & $\mathrm{mH}$ \\
Tegangan & 12 & volt \\
\hline
\end{tabular}

Dalam menentukan profil induktansi dengan melihat impuls arus pada salah satu fasa, diberikan pulsa $10 \mathrm{kHz}$ pada saklar. Gambar 7 disajikan rangkaian untuk mengetahui profil induktansi menggunakan pulse generator.

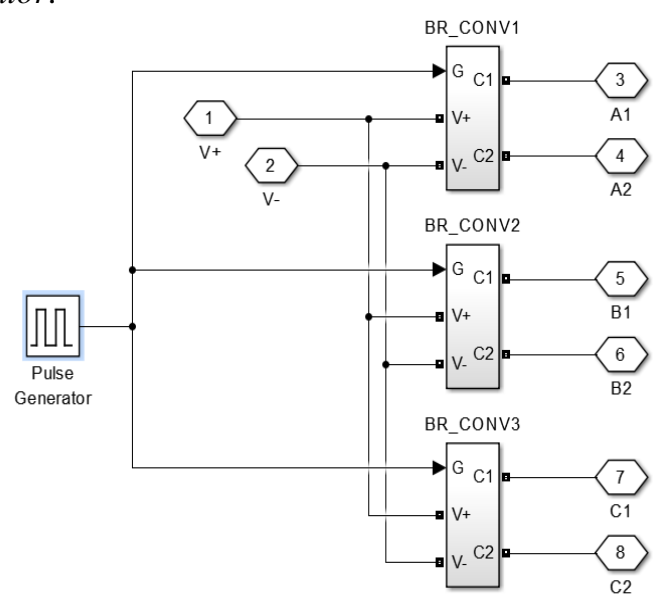

Gambar 6. Proses impuls arus pada belitan stator

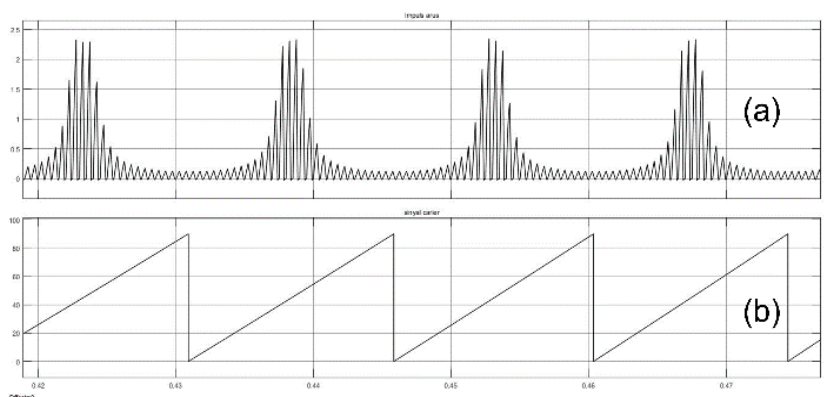

Gambar 7. Hasil simulasi (a) impuls arus (b) sensor posisi

Untuk mengetahui profil induktansi pada SRG yaitu dengan mengacu pada nilai impuls arus, semakin kecil nilai impuls arus maka nilai profil induktansi semakin besar. Hal ini dibuktikan dengan letak nilai puncak pada sensor posisi semakin tinggi maka nilai induktansi semakin besar

Setelah mengetahui posisi rotor maka dapat menentukan sudut penyalaan pada SRG yang tepat sehingga dapat bekerja dengan optimal. Kondisi sudut penyalaan ditunjukkan pada Tabel 2.

Tabel 2. Kondisi sudut penyalaan pada simulasi

\begin{tabular}{ccc} 
Kondisi & Fasa & Sudut Penyalaan $\left({ }^{\circ}\right)$ \\
\hline \multirow{2}{*}{ I } & A & $82-22$ \\
& B & $22-52$ \\
& C & $52-82$ \\
\hline \multirow{2}{*}{ II } & A & $80,5-22$ \\
& B & $20,5-52$ \\
& C & $50,5-82$
\end{tabular}

Dari Tabel 2. menunjukkan dua kondisi sudut penyalaan dengan lebar pulsa kendali yang berbeda. Pada Kondisi I memiliki lebar pulsa kendali sebesar $30^{\circ}$ mekanik sedangkan pada kondisi II memiliki $31,5^{\circ}$ mekanik. Sudut penyalaan pada Kondisi II mengalami overlap karena sesuai dengan analisis pada penelitian lebar pulsa kendali antar fasa sebesar $30^{\circ}$. 


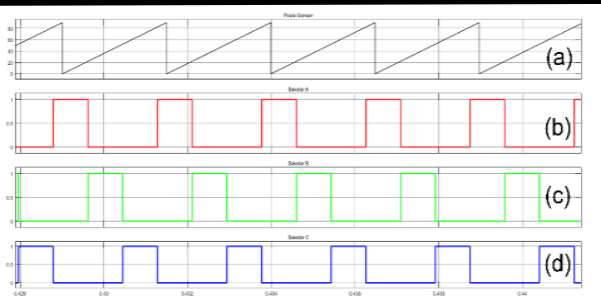

Gambar 8. Hasil simulasi gelombang (a) posisi rotor (b) sudut penyalaan A (c) sudut penyalaan B (d) sudut penyalaan C pada kondisi I

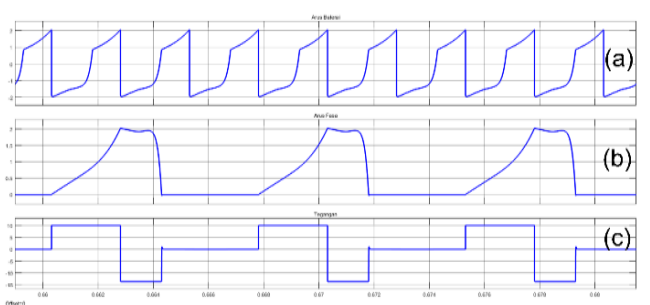

Gambar 9. Hasil simulasi (a) arus sumber DC (b) arus fasa (c) tegangan fasa pada kondisi I dengan kecepatan rotor 2000 RPM

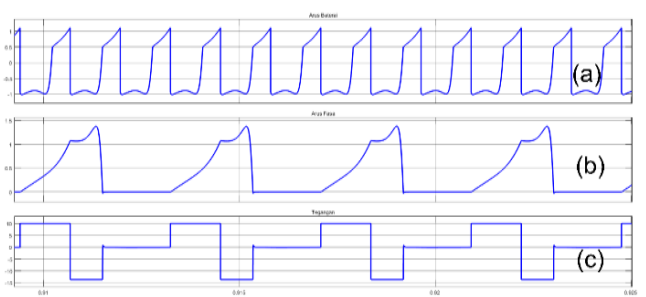

Gambar 10. Hasil simulasi (a) arus sumber DC (b) arus fasa (c) tegangan fasa pada kondisi I dengan kecepatan rotor 4000 RPM

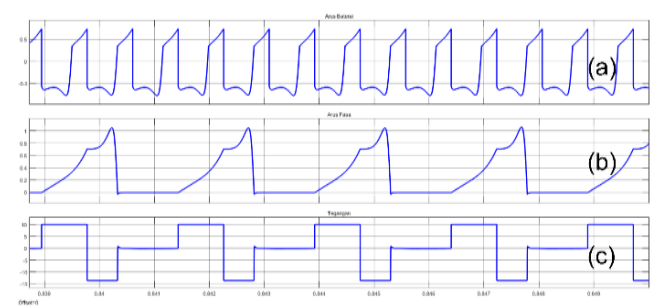

Gambar 11. Hasil simulasi (a) arus sumber DC (b) arus fasa (c) tegangan fasa pada kondisi I dengan kecepatan rotor 6000 RPM

Hasil simulasi pada Kondisi I dengan kecepatan rotor yang berbeda, menghasilkan bentuk arus sumber DC dan arus fasa yang berbeda. Semakin tinggi kecepatan rotor maka semakin besar nilai back-EMF maka menandakan hasil keluaran daya optimal.

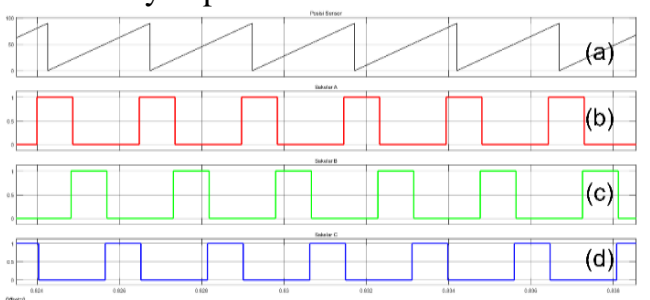

Gambar 12. Hasil simulasi (a) posisi rotor (b) sudut penyalaan A (c) sudut penyalaan $\mathrm{B}$ (d) sudut penyalaan $\mathrm{C}$ pada kondisi II

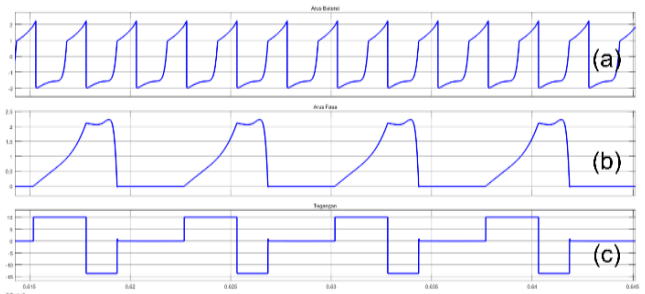

Gambar 13. Hasil simulasi (a) arus sumber DC (b) arus fasa (c) tegangan fasa pada kondisi II dengan kecepatan rotor 2000 RPM

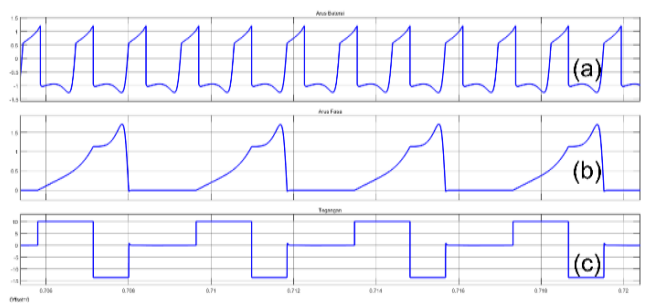

Gambar 14. Hasil simulasi (a) arus sumber DC (b) arus fasa (c) tegangan fasa pada kondisi II dengan kecepatan rotor $4000 \mathrm{RPM}$

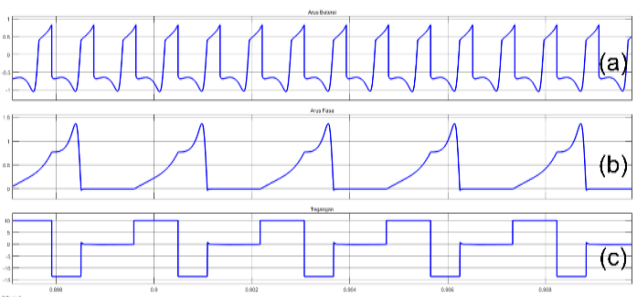

Gambar 15. Hasil simulasi (a) arus sumber DC (b) arus fasa (c) tegangan fasa pada kondisi II dengan kecepatan rotor 6000 RPM

Dari hasil keluaran gelombang pada simulasi diatas, didapat pada Kondisi II menghasilkan arus sumber DC dan arus fasa yang lebih menonjol dibanding Kondisi I. hal ini dikarenakan pada Kondisi II mengalami mengalami overlap dimana daerah arus yang dibangkitkan lebih luas pada Kondisi II daripada daerah arus Kondisi I, sehingga Kondisi II menghasilkan back-EMF lebih besar dari Kondisi I

B. Hasil Pengujian Alat Prototype

Untuk mendukung metode analisa maka dilakukan pengujian pada alat prototype. Pengujian alat ini berdasarkan dengan kondisi pada simulasi.

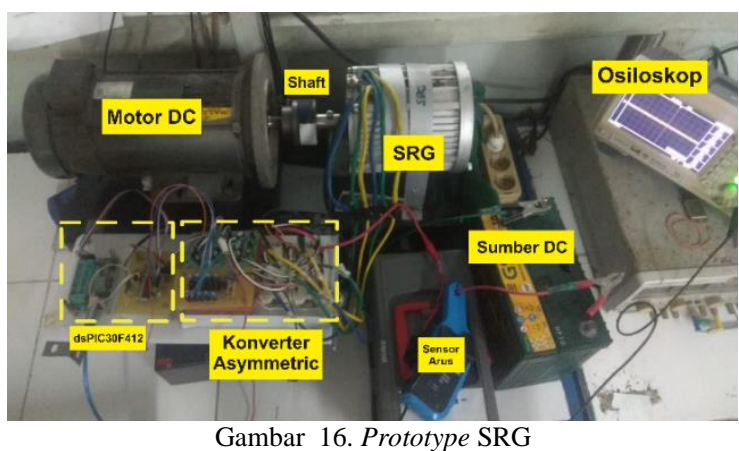

Pengujian pada prototype terdiri dari SRG tiga fasa, mikrokontroler dsPIC30F4012, konverter asymmetric menggunakan IGBT. Berikut ini adalah parameter yang akan digunakan pada simulasi disajikan pada Tabel 3. 


\begin{tabular}{lcc}
\hline \multicolumn{3}{c}{ Tabel 3. Parameter prototype SRG } \\
\hline \multicolumn{1}{c}{ Parameter } & Nilai & Satuan \\
\hline Stator & 12 & - \\
Rotor & 8 & - \\
Resistansi & 3.3 & Ohm \\
Induktansi & 1.4 & $\mathrm{mH}$ \\
Tegangan & 12 & volt \\
\hline
\end{tabular}

Untuk mengimplementasikan prototype dengan sudut Kondisi I dan Kondisi II akan tetapi motor DC pada alat prototype hanya mampu berputar maksimal 1800 RPM.

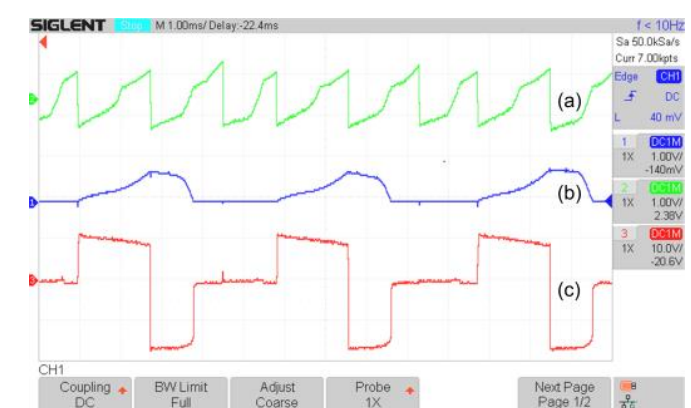

Gambar 17. Hasil pengujian prototype (a) arus sumber DC (b) arus fasa (c) tegangan fasa pada kondisi I dengan kecepatan rotor 1800 RPM

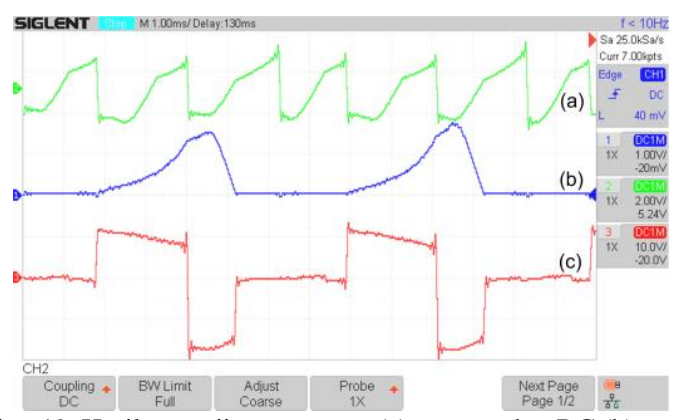

Gambar 19. Hasil pengujian prototype (a) arus sumber DC (b) arus fasa (c) tegangan fasa pada kondisi II dengan kecepatan rotor 1800 RPM

Hasil pengujian prototype bentuk arus fasa berbeda dengan bentuk arus fasa simulasi. Hal ini dikarenakan kecepatan pada pengujian prototype lebih rendah dari nilai kecepatan simulasi.

\section{KESIMPULAN}

Hasil simulasi dan pengujian alat prototype menunjukkan dengan menggunakan profil induktansi sebagai referensi penentuan sudut penyalaan dan kecepatan putaran rotor SRG dapat menghasilkan daya yang optimal.
Hal ini dibuktikan dengan nilai back-EMF yang lebih besar hal itu dapat dilihat hasil keluaran arus sumber DC. Sesuai dengan pengujian bahwa penyalaan sudut fasa lebih optimal ketika kondisi penyalaan sudut fasa mengalami overlap. Sudut penyalaan yang optimal adalah $80,5-22^{\circ}$ dengan kecepatan

6000 RPM. Hasil simulasi yang optimal dapat digunakan sebagai parameter dalam pengimplementasian prototype.

\section{REFERENSI}

[1] D. A. Torrey, "Switched reluctance generators and their control," IEEE Trans. Ind. Electron., vol. 49, no. 1, pp. 3-14, 2002, doi: 10.1109/41.982243.

[2] P. Kerdtuad and S. Kittiratsatcha, "Study of maximum power conversion of a switched-reluctance generator," ECTI-CON 2011 - 8th Electr. Eng. Electron. Comput. Telecommun. Inf Technol. Assoc. Thail. - Conf. 2011, no. 1, pp. 633-636, 2011, doi: 10.1109/ECTICON.2011.5947919.

[3] S. Sartori, M. Basu, M. Farrell, and A. Tortella, "Simulation and analysis of switched reluctance generator for renewable energy applications," Proc. - 2016 51st Int. Univ. Power Eng. Conf. UPEC 2016, vol. 2017-Janua, pp. 1-6, 2016, doi: 10.1109/UPEC.2016.8114081.

[4] S. Mapa, R. Maheswari, and G. Bhuvaneswari, "Maximum Power Point Tracking Using a Novel Current Control Strategy in an SRG Based Variable Speed Wind Energy Conversion System," India Int. Conf. Power Electron. IICPE, vol. 2018Decem, pp. 1-5, 2018, doi: 10.1109/IICPE.2018.8709471.

[5] M. Korkosz and A. Powrózek, "The influence of control parameters on energy efficiency of switched reluctance generator for vehicle applications," E3S Web Conf., vol. 14, 2017, doi: 10.1051/e3sconf/20171401037.

[6] M. Amanullah, S. Farooq, and S. Viswanathan, "Modeling and simulation of a biofilter," Ind. Eng. Chem. Res., vol. 38, no. 7, pp. 2765-2774, 1999, doi: 10.1021/ie9807708.

[7] S. S. Ahmad and G. Narayanan, "Modeling of Single-Pulse Operated Switched Reluctance Generator and Its Verification," IEEE Trans. Ind. Appl., vol. 56, no. 5, pp. 4966-4976, 2020, doi: 10.1109/TIA.2020.3005586.

[8] L. J. Lemes, V. Regis Bernardeli, L. C. Gomes, D. Alves De Andrade, G. P. Viajante, and M. Antonio Arantes De Freitas, "Dynamic Analysis of Self-excited SRG Operating in Open Loop," 2019 IEEE 15th Brazilian Power Electron. Conf. 5th IEEE South. Power Electron. Conf. COBEP/SPEC 2019, 2019, doi: 10.1109/COBEP/SPEC44138.2019.9065484.

[9] V. Nasirian, S. Kaboli, and A. Davoudi, "Output power maximization and optimal symmetric freewheeling excitation for switched reluctance generators," IEEE Trans. Ind. Appl., vol. 49, no. 3, pp. 1031-1042, 2013, doi: 10.1109/TIA.2013.2253438.

[10] P. C. Buck, B. Fahimi, and P. T. Balsara, "A Phase Current Peak Prediction Technique to Increase the Output Power of Switched Reluctance Generators for Wind Turbines," 2019 IEEE Energy Convers. Congr. Expo. ECCE 2019, pp. 5244-5250, 2019, doi: 10.1109/ECCE.2019.8912691. 